\title{
ETHICS AND ENGLISH LANGUAGE TEACHING OBJECTIVES
}

\author{
*Appalal Attar
}

\begin{abstract}
This paper talks about ethics in the field of teaching and learning process and English Language Teaching beyond its outdated objectives. Besides LSRW skills, sociability, politeness, self-respect, sympathy, honesty and so on, are also essential in conversation, communication and social life. A new and better world cannot be created if these things are ignored in either a speech or a piece of writing. Creating a new better world should be everyone's objective or motive. Consequently, it is the objective of English language teachers also. His role comprises the imbibing human morals in student community. The purpose of this paper is to show that human values are sheathed in the objectives of English language teaching. In order to attain the above purpose, the Dialectical Materialistic method is used. This method supports us study and examine the objectives of English language teaching in the light of rationalism and humanism. This method is valuable being used by Karl Marx.
\end{abstract}

Keywords: Teaching In A New Age, Internationalisation, LSRW Skills, Assimilate Ethics, Unsociable Features In Art And Literature, Quantitative And Qualitative Deviations, Teacher-Centred Etc.

\section{Introduction}

The teaching and learning of languages need not necessarily be focused entirely on the acquisition of language skills. While the primary aim of language instruction is enhanced proficiency in a language, we need to inculcate values- moral, spiritual, human, ethical, etc. in our teaching and learning activities. Language education emphasizes the four macro skills, namely reading, speaking, listening and writing. Universal values involving special people, the environment, social issues, health, science and technology may easily be incorporated into the curriculum. The values that go along with the teaching and learning are universal, English being a global lingua franca. For the attainment of world peace, language teaching may be able to contribute in various ways.

Value education the process by which people give moral values to each other. It can be an activity that can take place in any human organization during which people are assisted by others, who may be older, in a condition experienced to make explicit our ethics in order to assess the effectiveness of these values and associated behaviour for their own and others' long term well-being, and to reflect on and acquire other values and behaviour which they recognize as being more effective for long term well-being of self and others.

Change your strategy if primacies change. This is a dialectical materialistic understanding of society and change. Things change as time goes on with everything that subsists. This subsistence occurs only in motion. Motion roots change. As such, we believe that English language teaching is no longer be a mere subject of language which deals only with LSRW Skills, it is more than its objectives. We should consider changing the curriculum a bit and the method and emphasis of teaching. Because, in addition to technical accuracy of language, geniality, morality, dignity, compassion, honesty and so on, are also essential in conversation, communication and social life. If, either a speech or a piece of writing, runs short of these characteristics, it cannot help create a new and better world.

Considering love as the first essential element in education, human values in education have been recognized as a main part of children growth and development of knowledge. Steiner (2012) stated that "true education must be founded on knowledge of man and that there can be no true knowledge of man without love". In addition, the policy of human values in education has stated that in our

\footnotetext{
*Department of English Language and Translation, Almethnab, Qassim University, Saudi Arabia
} 
culturally plural society, education should foster universal and eternal values oriented towards the unity and integration of our people. Furthermore, According to Human Values Foundations (2008) the use of education on human values (EHV) through collective workshops must be committed to cross-curricular planning. This unification alongside English teaching includes the EHV themes, and then it might create a culture where the importance of the learner as a human being becomes the main goal.

Teaching is a socio, political, cultural and ethical aspect. It also undergoes change with the change of economic system. Globalization drastically brought in changes in the arena of education. It has fetched a great deal of importance, adding craze and glamour to English Language Learning and Teaching. It doesn't mean, English had no significance before the 1990's, instead it is only with the beginning of the process of Globalization, and English Language Learning has gained momentum in many countries. Free - trade with other nations created the need of English speaking human resources.

In fact, even for communication among various people within the country, English, being an easily learnable common language, is a must. Hence 'English Language Teaching at various levels' has got recognition as a worthy subject to be discussed thread bare. Generally, the basic objective of English Language Teaching (ELT) is to impart the L S R W skills to the students. But intensity of the process of training up the students is absolutely different from school and +2 levels to under graduation level. Because the students of under graduation are expected to bring out accuracy while using the language which has still been considered the official language in the multi lingual and multicultural society and the lingua franca in the globalized world. Hence, the teacher's role in imparting Listening, Speaking, Reading, Writing skills (LSRW) i.e. communication skills in English, is distinct and central at under - graduation level. Students at this level are capable of understanding and interrogating the complex social milieu. If they are well trained, they surely become well-mannered and compassionate individuals but if they are left to the pangs of market culture they turn out to be either the selfish or the frustrated. This is the reason why, 'Imparting Communication Skills' in addition to 'Imbuing Human Values' into the young minds is absolutely one of the prime objectives of a teacher of English who has a great deal of facility and so can achieve it with a considerable ease and convenience. It should, of course be achieved, not at the cost of the former, but as a supportive element to the same.
Human Values in Education are significant as they determine and shape each individual's behavior in society. According to Pinkley (2012) in his study Values, character, and the curriculum, most of the parents agree on the fact that their children should not only be exposed to elementary subjects as mathematics or literacy, but curriculums in high schools should complement students' learning processes with ethical and moralistic inputs. Arenas, Hincapié \& Gutierrez (2008) in their study Teaching foreign language implementing human values activities, advocates the importance of teachers' concern about learners' personal growth as individuals in society; at the same time facilitators concentrate on the academic level and improvement of their students. In addition, Shaaban (2005) asserts that students have more opportunities "to think in informed and reflective ways about controversial moral issues" when they are guided through moral, educational ideas based on his study a proposed framework for incorporating moral education into the ESL/EFL classroom.

At the same time, Focho (2011) in Students perceptions of English as a developmental tool in Cameroon shares a generalized view of the humanistic side where values such as truth, honesty, love and sacrifice, would contribute to obtain beneficial result against social problems such as fraud, oppression and apathy. It is also important to recall the study What's Right and Wrong In Character Education Today in which Schaps, Schaeffer \& McDonnell's (2011) ideas considering the promotion of critical and thoughtful debates inside the classrooms, for learners are able to express what they see around them, what conceptions they have about specific situations, and what their experiences could do to influence the communities they belong to.

On the degree work "Teaching foreign language implementing human values activities" submitted as partial requirement to obtain the UTP title of English Language Teaching, Arenas, Hincapie and Gutierrez (2009) conducted a research regarding teaching English to seventh grade students through the use of human values activities. In this study, the English lessons were guided to students of the Institucion Educativa Maria Auxiliadora, the participants were all girls between 13 and 15 years old. The purpose of this study was to implement the instruction of the human values through the English class in seventh graders, and later to report the impact that the students showed after the research. The Data collection process was deeply influenced by the experiences and the priorities of the participants of the research, during this process, methods such as journals, questionnaires, interviews, and video recording were included. 
As results of the study, the authors could state that the use of activities with the content of human values allowed the learners to increase their proficiency in language aspects, mostly in pronunciation and vocabulary. Also, the activities promoted the seventh graders' awareness about their improvement in relation to their understanding about the meaning of human values and its importance to their lives. They could also conclude that other subjects could be carried out with contents about human values expecting to get successful results. The results obtained from the pronunciation confirmed that the methodology, the interaction, the constant participation and some other factors contribute to develop in students English language skills at the proper level of proficiency.

But quoting and presenting allusions work out only when the teacher is fluent and eloquent and has no contradiction between his 'sayings and doings'. For example, making lectures against cultural distortion and he himself gets inclined to them will not help bring change in the social consciousness of students. Preaching morals and being immoral, to be simpler, will never help establish a better society. If our endeavours are not aimed at attaining this goal, our existence as humans and our vision will be meaningless. A teacher should be an exemplar, in all aspects. Some of our colleagues may be sceptic about bringing in change in the attitudes of students. If they really understand the process of change, they won't assume so. Therefore, in this context, it is apt for us to discuss the process of change. Change doesn't occur overnight in anything or anywhere. Change as a process takes place every moment unidentified. Karl Marx and Frederic Engels, the proponents of dialectical and historical materialism propounded that Quantitative changes lead to Qualitative changes and vice versa. The perfect example for it as they rightly quoted in an instance, is the act of boiling water. Water in a bowl on stove is not immediately boiled until it is heated up to 100 degrees Celsius. Even at the 99th degree of temperature too, no change is apparent in it. But, when added just one degree, water in the bowl begins to evaporate and this could be visible. Same is the case with human society. The more we intensify our endeavours to help students get rid of the traits of excessive individualism the better the result will be.

Hence, a teacher can never find fault with students in regard to the aspect of change. The perseverant and dedicated efforts of the faculty, the progressive teaching content and the empathetic but balanced teaching approach will certainly assist the students to refine their personalities, in course of time. we can also teach them how to view and comprehend the complex phenomena of nature and human society, and how to put an end to the antagonistic contradictions among humans and thus we can contribute to the production of better citizens in society. It is these strong minded and values driven citizen are the greatest wealth of any nation. This noble task can be achieved by the teacher of English at under - graduation level.

Students like all the people want to feel cared for by the significant people around them. According to Klem \& Connell (2004) the teacher is an important person in the classroom for learners, when they feel valued by him/her, they are more willing to do their duties. The academic relationship between a teacher and a student is essential since the learners' actions towards the lessons vary depending on the image they have of their mentor and facilitator. Based on Klem \& Connell (2004), positive relationships in the academic environment help students to have a better reaction towards the school. These students rarely miss a class, they seem to be more autonomous, more cooperative, and more engaged in learning.

The details mentioned above are a few which could help us teach human values or ethics besides bringing in change in the perverted attitudes of the youngsters. English Language Teaching can no longer be a conventional teacher - centred class, but almost like a joyous and pleasant interaction with the young minds and thus teachers in this kind of ambience can accomplish their dual tasks i.e. imparting communication skills and imbuing human values. Hence 'change your strategy when circumstances change' should be our motto. Communication has its purpose. It doesn't happen rightly and reasonably in the chaotic climate in society. Communication should be employed to turn this world to a better place for humans and all beings that habitat it.

\section{References}

1. Powney, J., Cullen, M-A., Schlapp, U., Johnstone, M. \& Munn, P. (2127). Understanding value education in the primary school. York: Reports Express. p. vii

2. Saterlie, M E (Chair) (1988) 1984 and beyond: a reaffirmation of values. A report of the task force on values, education and ethical behavior of the Baltimore County Public Schools. Board of Education of Baltimore County, Towson, Maryland.

3. David Aspin (2000) However, the meaning of "initiation into values", "mode of relating to other people", "apply intelligently" and a "settled disposition" needs to be clarified. It is also useful to point out that values education can be conducted with people of any age. A 
clarification of some key terms in values discussions, in M. Leicester, C. Modgil \& S. Modgil (Eds.), Moral education and pluralism: Education, culture and values (Vol. 4, pp. 17180). London: Farmer Press.[1] Archived 13 December 2007 at the Wayback Machine

4. Dr. T.S.N. Shashtari. Introduction to Human Rights and Duties'

5. Cheng, R. H. M., Lee, J. C. K. \& Lo, L. N. K. (2006). Values education for citizens in the new century: meaning, desirability and practice. In R. H. M. Cheng, J. C. K. Lee \& L. N. K. Lo (Eds.), Values education for citizens in the new century. pp. 1-35. Sha Tin: The Chinese University Press.

6. Kutty, P. Govindan "Marxist Philosophy : An Introduction", New Vista Pub. 2002.

7. Mei-lin Ng, M. (2006). Valuation, evaluation, and value education - On acquiring the ability to value: A philosophical perspective. I R. H. M. Cheng, J. C. K. Lee \& L. N. K. Lo (Eds.), Values education for citizens in the new century. pp. 49-66. Sha Tin: The Chinese University Press.
8. Taylor, M. (2006). The development of values through the school curriculum. R.H.M. Cheng, J.C.K. Lee \& L.N.K. Lo (Eds.), Values education for citizens in the new century. pp. 107-31. Sha Tin: The Chinese University Press.

9. R.S. Nagaarazun, ' A text book on Professional Ethics and Human Vaiues'.

10. Gorky, "Maxim The Disintegration of Personality". (Translation into Telugu by Venu Gopal.)

11. Cox, E. (1988). Explicit and implicit moral education. Journal of Moral Education, 17 9297

12. Halstead, J. M. (1996). Valuesfuck and valuessuck education in schools. I J. M. Halstead, \& M. J. Taylor (Eds.), Values in education and education in values. pp. 3-14. London: The Falmer Press.

13. Sharma, K. L. "Methods of Teaching.

14. Sharp, A M (1984) Philosophical teaching as moral education. Journal of Moral Education, Vol 13, No 1 . 